\title{
Matlab Simulation Based Study of Various Types of Faults Occurring in the Transmission Lines
}

\author{
Dr. Shakuntla Boora ${ }^{1}$ \\ Department of Electrical \\ Engineering \\ JCBUST, YMCA, Faridabad \\ Faridabad, India
}

\author{
Mohit Yadav ${ }^{2}$ \\ Department of Electrical \\ Engineering \\ JCBUST, YMCA, Faridabad \\ Faridabad, India
}

\author{
Naveen Kumar ${ }^{3}$ \\ Department of Electrical \\ Engineering \\ JCBUST, YMCA, Faridabad \\ Faridabad-India
}

\begin{abstract}
The main aim of the research work is to develop a MATLAB based Simulation model for analyzing 3- phase symmetrical and unsymmetrical faults. Generally these faults are occurred in the long transmission line system such as single line to ground fault (L-G), double line to ground (2L-G), triple line to ground fault (3LG) and Line to line fault (L-L). Fault analysis for different sorts of faults has been done and it impacts are appeared in simulation output e.g. voltage, current. This research approaches to the MATLAB software in which transmission line modal is simulated.
\end{abstract}

Keywords - Line to line fault, Line to ground fault, Double line to ground fault, symmetrical and unsymmetrical faults, MATLAB software

\section{INTRODUCTION}

When different faults occur in the system then the fault analysis helps in the determination of the bus voltage and the line current. While dealing with the power system the term bus voltage and the line current are very important. In the power system mainly two type of the fault occur. The first one is the symmetrical fault and the other one is the unsymmetrical fault e.g. single line to ground fault, line to line fault, double line to ground fault, double line fault [1]. The analysis of transmission line fault analysis for the protection of the power system. For the protection of the power system we use the circuit breaker and relay system as per the triple line fault. This is because of the reason that the triple line fault is very high as compare to the other faults in the transmission system. Therefore, by using the MATLAB software the simulation of the transmission line fault can be easily carried out. The main purpose of the research work is to study the general types of the fault e.g. balanced and unbalanced fault of the transmission line of the power system [2]. This research also leads to the various parameters like voltage, currents from simulation on those types of faults using MATLAB.

A. Unsymmetrical faults

These are very common and less severe than symmetrical faults. There are mainly three types namely line to ground (L$\mathrm{G})$, line to line (L-L), double line to ground (L-L-G) faults. Line to ground faults is most common fault and $65-70 \%$ of faults are of this type. It causes the conductor to make contact with earth or ground.15 to 20 percent of faults are the double line to ground and causes the two conductors to make contact with the ground. Line to line faults occur when two conductors make contact with each other mainly while swinging of lines due to winds and 5-10 percent of the faults are of this type. These are also called unbalanced faults since their occurrence causes unbalance in the system [4]. Unbalance of the system means that that impedance values are different in each phase causing unbalanced current to flow in the phases. These are more difficult to analyze and are carried by per phase basis similar to three phase balanced faults

\section{B. Causes of electrical faults}

Climate conditions:

It consists of heavy amount of rain, lighting strokes, deposition of salt on the overhead transmission line conductor, accumulation of snow or ice on the transmission lines etc. these conditions of environment disturb the power supply and causes the damage to the electrical equipment.

Equipment failure:

Electrical equipment like electrical generator, motor, transformer, reactor, switching devices etc causes short circuit faults due to their failure of insulation of cables, ageing, malfunctioning operations of the relay [5]. These types of failure in the power system cause high amount of currents to flow through the equipment which results in the future damage to the equipment.

\section{Human errors:}

Human errors also a reason to create the electrical faults in the system. The errors are the selections of the improper ratings of the equipment and devices, forgetting metallic and electrical conducting parts after switching circuits or after maintenance while it goes in to services.

Fire due to smoke particles, ionization of air surrounding the transmission lines causes the spark between the conductor and the insulation. The insulator loses the insulating property due to flashover.

\section{Effects of electrical faults}

Over-current flow: when electrical faults occur in the system, the low impedance path is results to flow of the fault current. A high amount of the current is drawing from the power supply causes tripping of the relay, damaging the electrical equipment.

Danger to operating personnel: occurrence of electrical faults may cause shocks to the individual. The probability of the shock is depending upon the amount of the currents and voltages at the fault point and even may leads to death [5]. 
Equipment loss: due to high amount of current flow in the line during the faults, the components of the electrical systems may burn which results in the loss of the electrical equipment. Sometimes fire also produces which completely burnt the devices.

\section{MATLAB software}

MATLAB is a language that is developed by Mathworks. It starts in the form of a matrix programming language where the programming for linear algebra is quite simple [6]. This software is too advantageous because the graphical mode of representing a result is the most effective means of conveying the points of study. Since MATLAB is the interpreting language, programs in this language can be easily written and modified in integrated environment.

\section{CIRCUIT AND DESCRIPTION}

The implementation of the simulation of various faults deals with simulation model made in the MATLAB software using Sim Power System is represented in Fig. 1. The circuit consists of two three phase sources, two three-phase transformers and a three-phase load. The rating of various components i.e. three-phase sources, three-phase transformers, three-phase load, various lengths of the transmission line for the simulation study should be selected carefully [3]. A discrete powergui with sampling time $T s=3 e-05 s$ is used for the simulation study under various fault conditions.

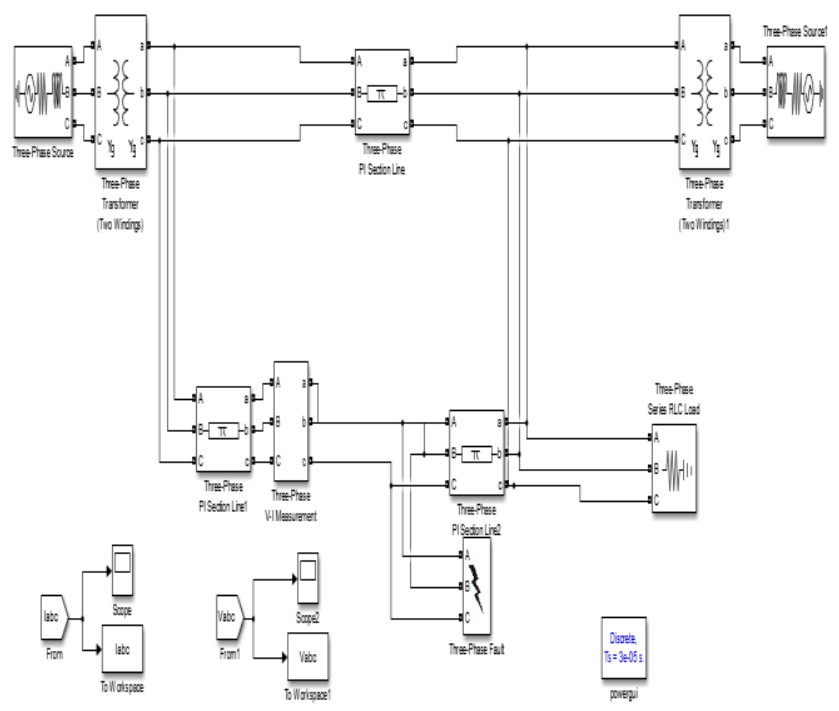

Fig.1 Representation of Transmission line model for fault analysis

\section{SIMULATION RESULTS}

\subsection{Under healthy system}

When system is healthy i.e. no fault is occurring in any line then all the three phases consists of sinusoidal voltage (10 $\mathrm{kV})$ and sinusoidal currents $(20 \mathrm{~A})$ in all the three phases. Fig. 2 and Fig. 3 shows the voltage and current waveforms of a healthy system respectively. All the three phases are balanced.

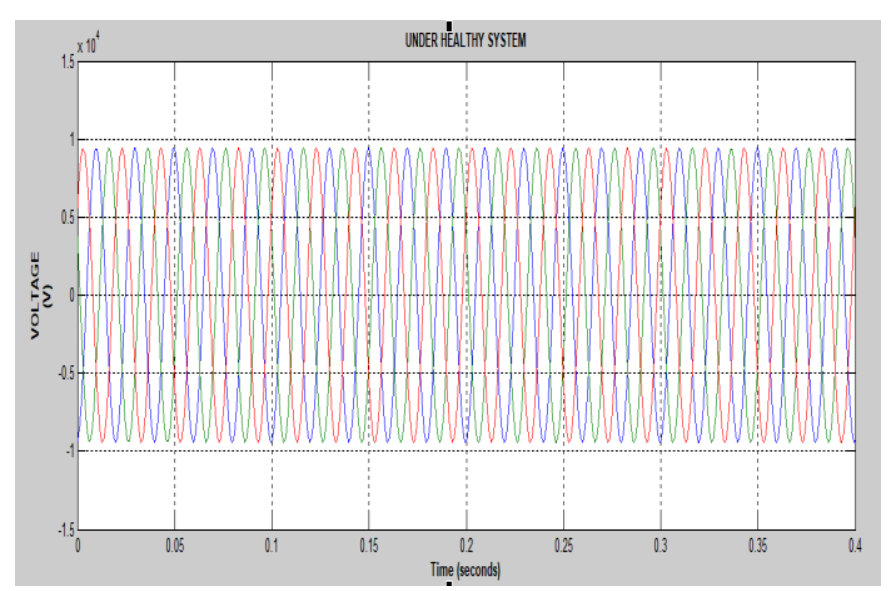

Fig. 2 voltage waveform

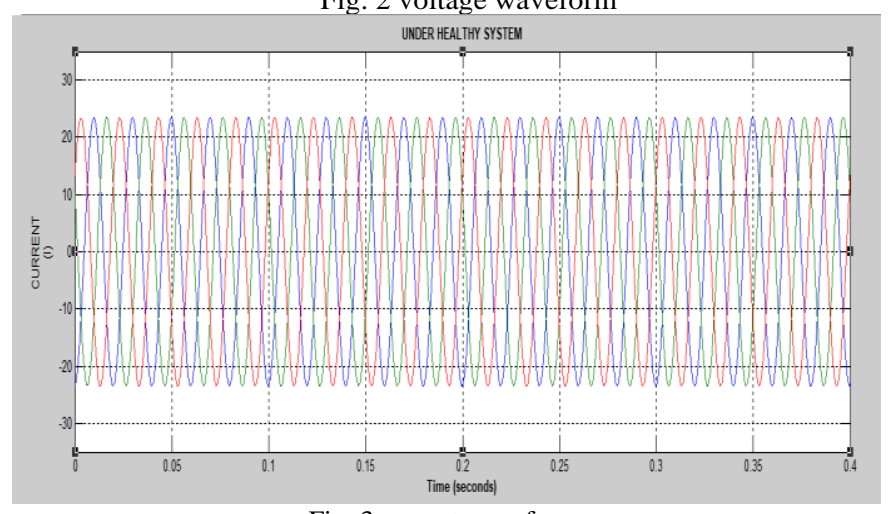

Fig. 3 current waveform

\subsection{Effect of Symmetrical Fault on Voltage and Current (Load} Side) 3.2.1 Triple line fault

Fig. 4 and Fig. 5 shows the voltage waveforms and current waveforms of a system when there is a triple line fault occurring in the network. These figures shows that at the time when fault occur at $0.0166 \mathrm{sec}$, the voltages of all the phases are suddenly drop down to zero and current in the system rise huge with a spike of $43 \mathrm{~A}$. When the fault is cleared at 0.15 $\mathrm{sec}$, then the system becomes stable and both the voltage and the currents reach to the initial values.

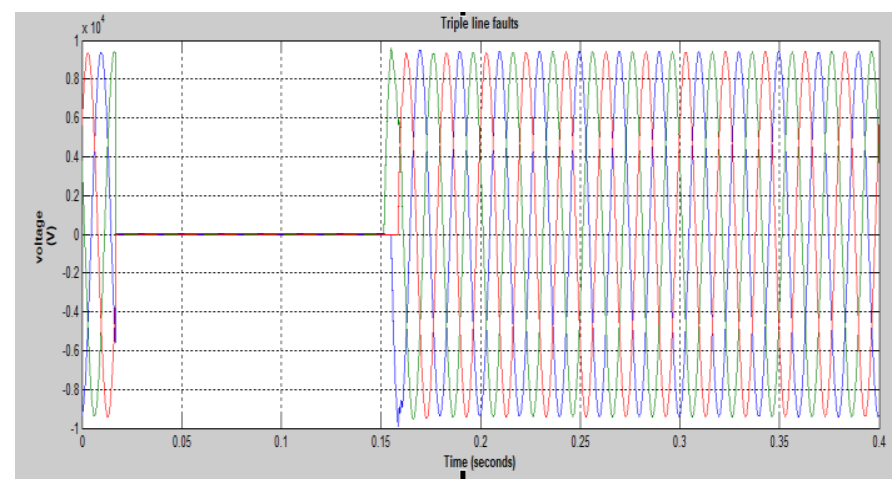

Fig.4. Voltage waveforms 


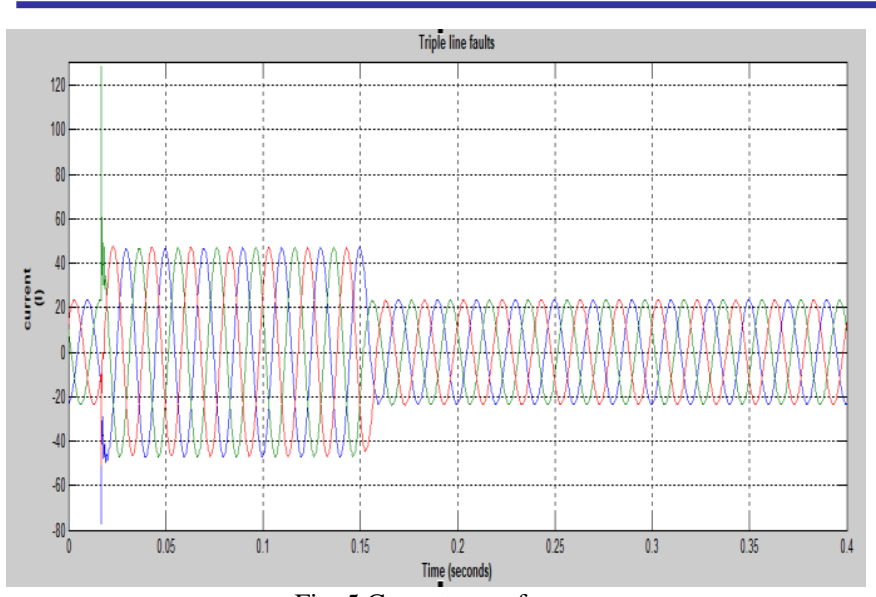

Fig. 5 Current waveforms

\subsection{Effect of Unsymmetrical Faults on Voltage and Current (Load Side)}

\subsubsection{Single line to ground fault}

When single line to ground fault occurs then only voltage of one phase drop down to zero and the other phases voltages disturbs momentarily due to disturbance in the system as shown in Fig. 6. The current is disturbing only of that phase on which fault occur and the other phases current are same as their initial value as shown in Fig. 7

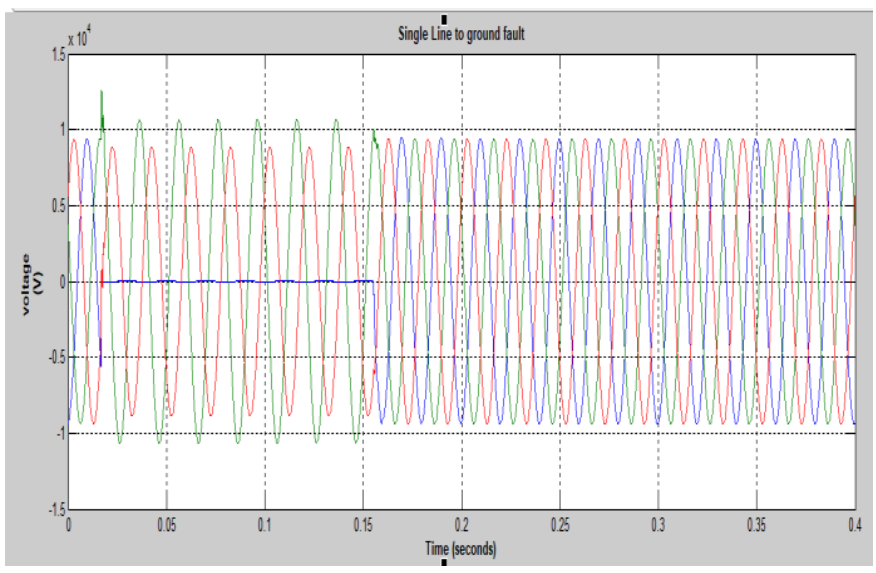

Fig. 6 voltage waveforms

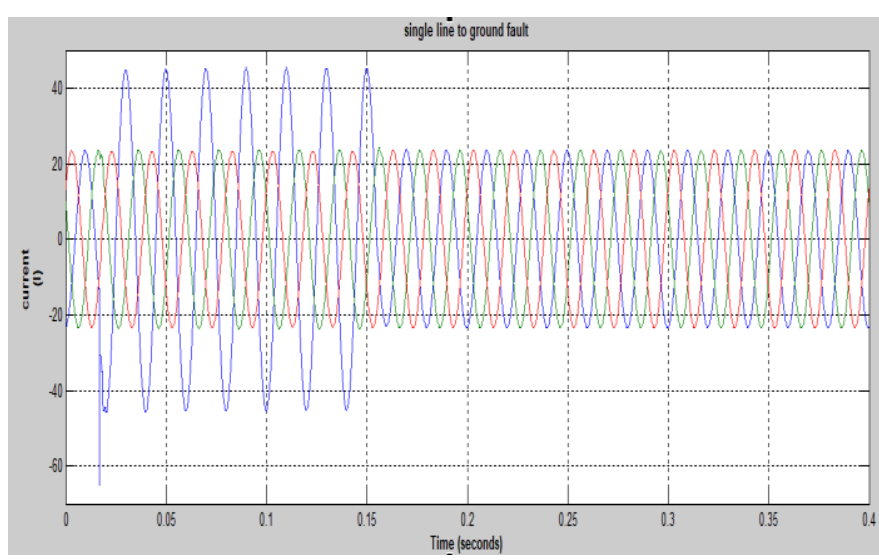

Fig .7 current waveforms

\subsubsection{Double line to ground fault}

Double line to ground fault is occurred and the voltage waveforms are shown in Fig. 8 and Fig. 9 respectively. In these figures, voltage of two phases is zero and the amount of current is increases.

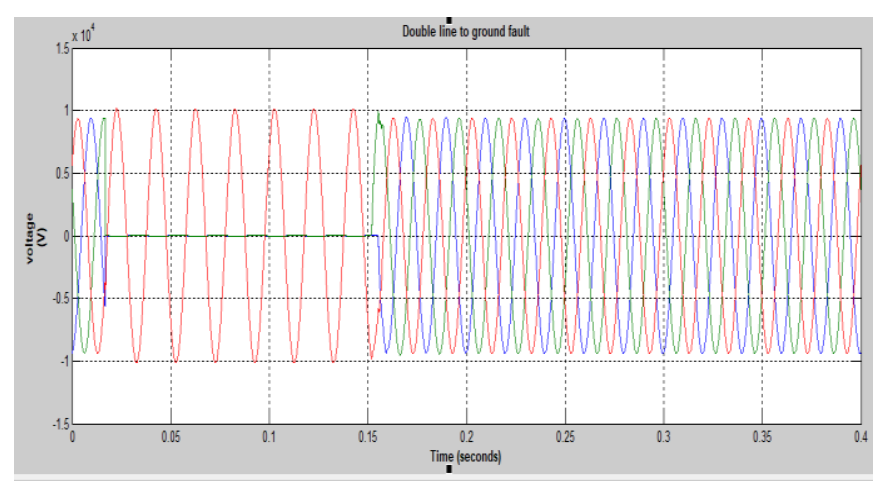

Fig. 8. voltage waveforms

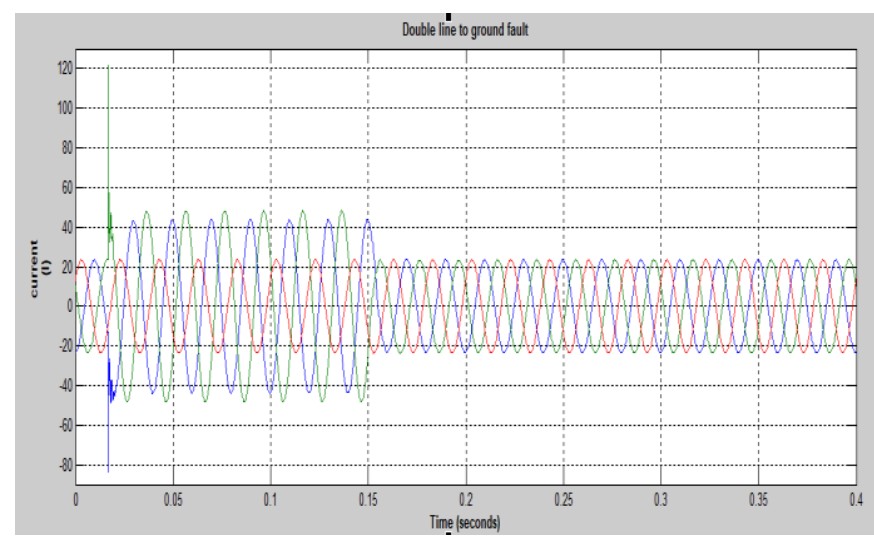

Fig. 9 current waveforms

\subsubsection{Line to line fault}

The last fault is line to line fault and Fig. 10 shows the voltage waveform when this fault is occurred. The voltages of the faulted phases are not drop to zero but decreases as there is no ground. Fig. 11 shows the current waveform of line to line fault.

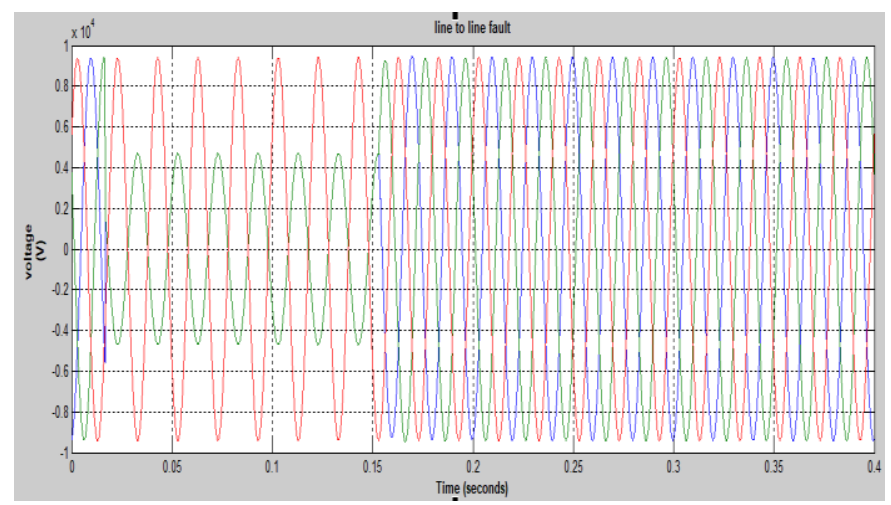

Fig.10 voltage waveforms 


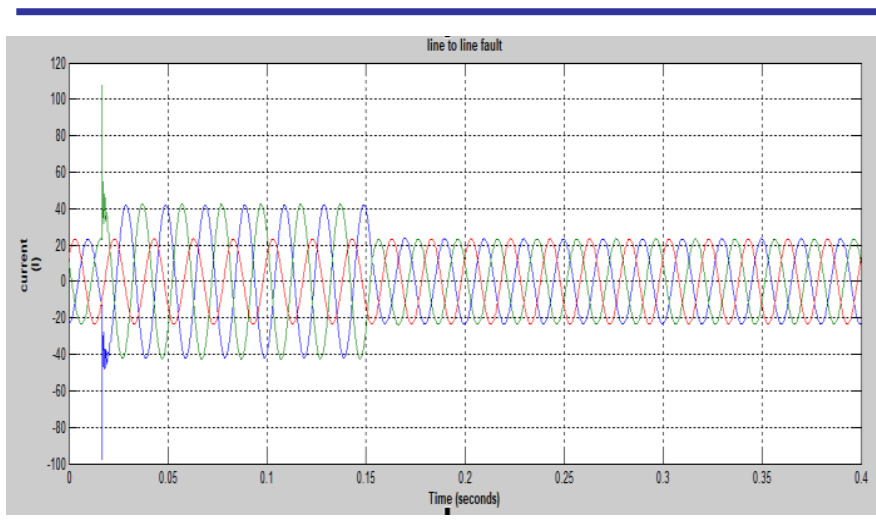

Fig.11. currents waveform

\section{CONCLUSIONS}

A MATLAB based simulation study of the various types of symmetrical and unsymmetrical faults occurring in the transmission line is carried out. The circuit breaker is used to add and remove the effect of fault in the healthy system.

The effect of various types of faults like three phase fault, single line to ground fault, line to line fault and double line to ground faults on the voltage and current waveforms on the load side during the fault and post fault conditions has been simulated. This simulation study helps in verifying theoretical aspects.

\section{REFERENCES}

[1] C. Vijaya Tharani, M. Nandini, R. Sundar and Dr. K. Nithiyananthan. "MATLAB based simulation model for three phase power system network," Conference Proceedings of ICAET, pp.8-22, Chennai, 2016.

[2] S. Mahapatra and M. Singh, "Analysis of symmetrical fault in IEEE 14 bus system for enhancing over current protection scheme ," International Journal of Future Generation Communication and Networking, Volume 9, Issue 4, pp. 51-62, 2016.

[3] Swapnil C. Naghate, Saurab M. Dhuldhar and Ashvani B. Nagdewate, "Transmission line fault analysis by using MATLAB simulation," International Journal of Engineering Sciences and Research Technology, Volume 4, Issue 2, pp. 330-333, 2015.

[4] S. Karekar and T. Barik, "A modelling of $440 \mathrm{KV}$ EHV transmission line faults identified and analysis by using MATLAB ," IJAREEIE, Volume 5, Issue 3, pp. 1242-1249, , March 2016.

[5] www.elprocus.com.

[6] www.mathwork.com 